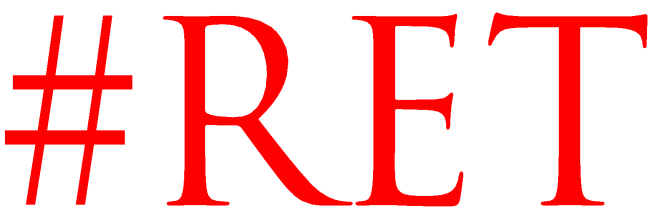

\title{
El Derecho Humano de Protección de Denunciantes de Corrupción a través de la Política Pública en México (2013-2019)
}

\author{
Arturo Miguel Chípuli Castillo1 \\ Universidad Veracruzana \\ México
}

RECIBIDO: 30 de mayo de 2020 ACEPTADO: 10 de julio de 2020

\begin{abstract}
RESUMEN: En México, durante largo tiempo la estrategia anticorrupción ha dejado de lado a los denunciantes de actos de corrupción. Su progresiva inclusión en el marco de políticas públicas conlleva la necesidad de que el Estado cumpla con ciertas obligaciones establecidas en el derecho internacional de los derechos humanos. De ahí que, en el presente texto, se estudian tres programas de política pública anticorrupción correspondientes al periodo 2013-2019, con el objeto de comprobar si en su diseño se contemplaron medidas de protección de denunciantes, conforme a los estándares internacionales. Nos centraremos en aquellas establecidas en el marco del Sistema Universal de Derechos Humanos y del Sistema Interamericano de Derechos Humanos, a los cuales pertenece México, y cuyos tratados y convenios internacionales le sujetan a un marco específico de responsabilidades internacionales.
\end{abstract}

PALABRAS CLAVE: Políticas Públicas, Denunciantes de Actos de Corrupción, Derechos Humanos.

CONTENIDOS: 1. Introducción. - 2. Metodología. - 3. La Protección de Denunciantes de Actos de Corrupción como Derecho Humano. - 3.1. Corrupción y Derechos Humanos. - 3.2. La Protección de Denunciantes de Actos de Corrupción como

\footnotetext{
${ }^{1}$ Doctor en Derecho y Maestro en Derecho Constitucional por la Universidad de Xalapa, Maestro en Derechos Humanos y Democracia por la FLACSO México, y Licenciado en Derecho por la Universidad Veracruzana. Actualmente labora como Investigador en el Instituto de Investigaciones Jurídicas de la Universidad Veracruzana.
} 
Derecho Humano. - 4. La Política Pública en materia de Protección de Denunciantes de Actos de Corrupción en México (2013-2019). - 4.1. El Programa para un Gobierno Cercano y Moderno (2013-2018). - 4.2. Programa Nacional de Combate a la Corrupción y a la Impunidad, y de Mejora de la Gestión Pública (20192024). - 4.3. Lineamientos para la Promoción y Operación del Sistema de Ciudadanos Alertadores Internos y Externos de la Corrupción. - 5. Política Pública y Protección de Denunciantes de Actos de Corrupción en México. - 6. Conclusiones.

- 7. Bibliografía.

\section{The Human Right to Protection of Whistleblowers through Public Policy in Mexico (2013-2019)}

ABSTRACT: In Mexico, the anti-corruption strategy has long eluded whistleblowers. Its progressive inclusion in the framework of public policies implies the need for the State to comply with certain obligations established in international human rights law. Therefore, in this text, three anti-corruption public policy programs corresponding to the period 2013-2019 are studied, in order to verify if their design considered whistleblower protection measures, in accordance with international standards. We will focus on those established within the framework of the Universal Human Rights System and the Inter-American System of Human Rights, to which Mexico belongs, and whose international treaties and conventions subject it to a specific framework of international responsibilities.

KEYWORDS: Public Policy, Whistleblowers, Human Rights. 


\section{INTRODUCCIÓN}

La corrupción en México es un problema añejo, que encuentra sus bases en el sistema político mexicano construido en la década de los treintas y cuarentas del siglo XX, caracterizado por una maquinaria política basada en la existencia de un partido hegemónico, con un fuerte sistema de gobierno corporativo de estilo vertical, sustentado en la concentración del poder en el presidente, y con un sistema de controles basado en las lealtades, la cooptación, los privilegios y la represión, que junto a un Estado de derecho parcial, generó una simbiosis que tuvo por efecto la ausencia de alternancia, la creación de elites de poder, y desde luego, la expansión de prácticas corruptas de la clase política (Bautista, 2017: 20-23). Durante las décadas siguientes, el país se hundiría en lo que Enrique $\mathrm{Krauze}^{2}$ ha denominado la "corrupción moderna", caracterizada por una expansión del sector público que trajo consigo un cambio en la escala de la corrupción, donde las historias de enriquecimiento incomprensible serian un lugar común.

Tras las elecciones de 1982, y luego de asumir el cargo como presidente de la república mexicana, Miguel de la Madrid Hurtado (1982-1988) refirió la necesidad de afrontar el problema de la corrupción, la cual habia aumentado radicalmente durante la administración de José López Portillo (1976-1982)3, cuestión que motivó la llamada "renovación moral de la sociedad", misma que involucró la reforma a diversos preceptos constitucionales en materia de responsabilidades del funcionariado público ${ }^{4}$, así como de los organismos de la Administración Pública Federal. Años más tarde, las reformas continuaron manifestándose, sobre todo mediante la incorporación de nuevos ámbitos de control interno y externo, así como de nuevos contenidos normativos cuyo objetivo era "perfeccionar" el sistema de responsabilidades en el servicio público (Chípuli, 2017: 209). Pese a lo anterior,

\footnotetext{
2 Krauze, E., 1995. Breve historia de la corrupción. Disponible en: https://www.ingenieria.unam.mx/dcsyhfi/material_didactico/Literatura_Hispanoamericana_Contem poranea/Autores_K/KRAUZE/Breve.pdf

${ }^{3}$ El sexenio de López Portillo marcó un antes y un después en la política mexicana, debido al caos económico y moral imperante en el país hacia el final de su gobierno. Por un lado, fue el primer gobierno latinoamericano en declararse incapaz de afrontar sus obligaciones financieras internacionales, con lo cual comenzó la llamada "crisis de la deuda latinoamericana" que eventualmente serviria para la adopción del modelo neoliberal en el país (Saxe, 1996: 155); y por el otro, el fracaso de la reglamentación en materia de responsabilidades de los servidores públicos, que generó un ambiente de impunidad en la investigación y sanción de actos de corrupción (Chípuli, 2017: 209).

${ }^{4}$ Principalmente del Título IV de la Constitución Política de los Estados Unidos Mexicanos: artículos 108, 109, 110, 111, 112, 113, y 114

${ }^{5}$ Posterior a la reforma de 1982 se crearon diversas leyes de responsabilidades de funcionarios públicos: Ley Federal de Responsabilidades de los Servidores Públicos, Ley Federal de Responsabilidades Administrativas de los Servidores Públicos y Ley Federal de Responsabilidad Patrimonial del Estado.
} 
el cambio de siglo trajo consigo pocos avances en la materia, a lo que se sumó una reducción del sector público, la colocación de empresarios (y de una lógica empresarial) en la administración pública (Bautista, 2017: 28), y la escalada en el clima de inseguridad y violaciones a los Derechos Humanos a partir de la estrategia contra el crimen organizado emprendida durante el sexenio de Felipe Calderón Hinojosa (2006-2012), los cuales, entre muchos otros motivos, llevaron de forma progresiva a la captura del Estado mexicano por parte de intereses particulares y poderes facticos.

Durante largos años, y debido en gran medida a la fuerte tradición de clientelismo en el sector público, en México se desconoció, ignoró e invisibilizó la relevancia de los whistleblowers (en lo subsecuente denunciantes de actos de corrupción o denunciantes) en la estrategia de combate a la corrupción6. Aunado a lo anterior, la falta de confianza en las instituciones públicas y de procuración de justicia, ha desincentivado el ejercicio de las denuncias, las cuales además son regularmente inhibidas por un ambiente de tolerancia, violencia, intimidación, amenazas laborales y acoso por parte de compañeros, superiores jerárquicos y personas ligadas a estos ${ }^{7}$.

En diciembre de 2012, Enrique Peña Nieto (2012-2018) asume la presidencia de la República mexicana, con la firme promesa de erradicar la corrupción, cuestión que motivó la inclusión de acciones y estrategias concretas en diversos programas de política pública (particularmente en los programas "México en Paz" y "Gobierno Cercano y Moderno"). Asimismo, se realizaron importantes avances normativos, como la reforma constitucional anticorrupción de 2015, la cual dio vida al Sistema Nacional Anticorrupción (SNA). No obstante lo anterior, el sexenio referido estuvo marcado por diversos y muy graves escándalos de corrupción que, pese a los avances referidos, puso en entredicho la política de combate a la corrupción en el país, evidenciando la simulación en muchos mecanismos de rendición de cuentas, entre ellos, la protección a denunciantes, la cual ya figuraba en la Ley General de Responsabilidades de los Servidores Públicos, y en el Programa para un Gobierno Cercano y Moderno (política pública de corte transversal aplicable a toda la administración Pública federal).

\footnotetext{
${ }^{6}$ Para llenar este vacío, y al margen del marco normativo, en México se han practicado las llamadas "filtraciones anónimas de actos de corrupción", como única vía para la denuncia. Esto debido a que la Ley Federal de Responsabilidades Administrativas de los Servidores Públicos limitaba el ejercicio de la denuncia a su forma escrita, a través de un procedimiento ante la contraloría interna o secretaría correspondiente, en quien quedaba la potestad discrecional sobre la aplicación de una sanción (Villanueva, 2007: 372)

7 En 1986, Gabriel Zaid esbozó una frase que parece resumir la problemática que se presenta en México "...la honestidad es tragicómica. Hay que disimularla, para no causar lastima o no causar problemas". Zaid, G., 1986, La propiedad privada de las funciones públicas, en Vuelta 120. Disponible en: https://sistemapoliticomexico.files.wordpress.com/2012/11/gabriel-zaid-propiedad-privada-delo-publico.pdf
} 
Finalmente, el proceso electoral del año 2018 marcó un importante viraje respecto a la hegemonía de los principales partidos políticos en México, donde resultó victorioso Andrés Manuel López Obrador, candidato por el partido Movimiento de Regeneración Nacional (Morena), motivado en muchos sentidos por el discurso anticorrupción emprendido en su campaña hacia la presidencia. En cerca de dos años, la implementación de su política anticorrupción ha sido controversial, con estrategias y resultados ambiguos. Empero, resulta de interés que, en este corto lapso de tiempo, se haya diseñado e implementado una política pública destinada al combate a la corrupción: el "Programa Nacional de Combate a la Corrupción y a la Impunidad, y de Mejora de la Gestión Pública" (2019-2024), el cual integró, entre sus acciones, la protección de denunciantes de actos de corrupción, así como el "Sistema de Ciudadanos Alertadores Internos y Externos de la Corrupción".

Con base en estos breves antecedentes en materia de combate a la corrupción en México, lo que en el presente trabajo interesa estudiar de forma concreta son los programas de política pública emprendidos durante el periodo 2013-2019 por el gobierno mexicano en materia anticorrupción y las estrategias emprendidas para la protección de denunciantes de actos de corrupción. Como ha quedado asentado en las líneas que preceden, la experiencia en este rubro se encuentra limitada a tres programas generales: el Programa para un Gobierno Cercano y Moderno (2013-2018), el Programa Nacional de Combate a la Corrupción y a la Impunidad, y de Mejora de la Gestión Pública (2019-2024), y los Lineamientos para la Promoción y Operación del Sistema de Ciudadanos Alertadores Internos y Externos de la Corrupción (2019-2024), mismos que se analizaran de forma general con la finalidad de establecer las estrategias y acciones emprendidas para garantizar el derecho humano de protección de denunciantes. Dicho derecho se encuentra primordialmente reconocido como un componente fundamental de la libertad de expresión y del derecho de acceso a la información pública, con un conjunto de obligaciones que deben ser observadas y cumplidas por el Estado mexicano, en razón de la firma y ratificación que el gobierno de la Republica y el Senado han realizado de los diversos tratados internacionales en materia de derechos humanos y combate a la corrupción ${ }^{8}$.

Derivado de lo antes señalado, el presente documento abordara, en primer lugar, lo relativo al derecho humano de protección de denunciantes de actos de corrupción (whistleblowers), así como su marco de obligaciones conforme al

\footnotetext{
${ }^{8}$ En México, el proceso para la aceptación de un Tratado Internacional consiste, grosso modo, en la aceptación y firma por parte del Presidente de la Republica (Artículo 89, fracción X Constitucional), y el ulterior sometimiento a la aprobación de la Cámara de Senadores, la cual se encuentra facultada para realizar el control de la política exterior (Artículo 76, fracción I Constitucional). Con su visto bueno, el Tratado Internacional se incorpora al ordenamiento jurídico nacional. En materia de Tratados y Convenciones que versen sobre Derechos Humanos, estos serán considerados como parte integral de la Ley Suprema del país (Artículo $1^{\circ}$ Constitucional), y sus obligaciones deben ser observadas por todas las autoridades del país, en el marco de sus respectivas competencias.
} 
derecho internacional de los derechos humanos (DIDH) y anticorrupción (principalmente el sistema universal e interamericano) para dar garantía efectiva al mismo. En segundo término, se analiza de forma general la política pública mexicana que, en el periodo 2013-2019, ha establecido acciones y estrategias de protección de denunciantes. Finalmente, en el último apartado, se evalúan de forma general sus componentes, a fin de establecer en qué medida cumplen con los estándares de la materia.

\section{METODOLOGÍA}

Para el logro del objetivo antes planteado se recurrirá parcialmente a la metodología del enfoque de derechos humanos. Dicho enfoque requiere tener presentes dos conjuntos de elementos: a) los estándares internacionales de derechos humanos, y b) los elementos transversales (mecanismos de exigibilidad, principio de igualdad y perspectiva de género, participación, etcétera). El presente documento se ceñirá al primero de estos conjuntos, derivado de lo cual, en primer lugar, se procede a la identificación de las obligaciones contenidas en las diversas fuentes de hard y soft law del DIDH, y sobre las cuales se construye un estándar en materia de protección de denunciantes de actos de corrupción.

A partir de las obligaciones referidas, se examinan tres programas de política pública: el Programa para un Gobierno Cercano y Moderno (2013-2018), el Programa Nacional de Combate a la Corrupción y a la Impunidad, y de Mejora de la Gestión Pública (2019-2024), y los Lineamientos para la Promoción y Operación del Sistema de Ciudadanos Alertadores Internos y Externos de la Corrupción. Esto con la finalidad de dilucidar en qué medida el marco internacional de obligaciones en materia de protección de denunciantes ha incidido en el diseño de las políticas públicas anticorrupción de México en el periodo 2013-2019.

\section{LA PROTECCIÓN DE DENUNCIANTES DE ACTOS DE CORRUPCIÓN COMO DERECHO HUMANO}

De forma general, a nivel global, se ha popularizado el uso del término whistleblower para referir a los denunciantes, alertadores o informantes de actos irregulares o de corrupción, empero, puede afirmarse que no existe una concepción unificada respecto del significado que involucra el término, pues este puede referir, entre muchas cosas, un acto de libertad de expresión, una herramienta anti-corrupción y un mecanismo interno de gestión de conflictos. En este sentido, puede afirmarse que se trata de un medio para promover tres cuestiones: primero, la rendición de cuentas en el sector público al permitir, tanto la revelación de información que resulta crítica para la vida pública, como para la divulgación de información sobre malas conductas al interior de las organizaciones. Segundo, establece un marco de protección a la persona frente a sanciones y 
amenazas de todo tipo. Finalmente, como herramienta de mejora de la gestión interna de las organizaciones, estableciendo mecanismos de rendición de cuentas y alertas tempranas (Banisar, 2011).

Respecto de los orígenes del término, Puñal García (2018: 205) señala que whistleblower fue utilizado por primera vez en 1970 por el abogado estadounidense Ralph Nader a fin de proteger a los ciudadanos de los Lobbies. El definió esta figura como un acto por el cual una persona que, creyendo que el interés público prevalece sobre el interés de la organización para la que trabajan, toca el silbato para anunciar que la organización está llevando a cabo una actividad corrupta, ilegal, fraudulenta o perjudicial. En este sentido, el propósito del término fue establecer una concepción que presentara de forma positiva a quienes eran conocidos como traidores o informantes9. Al respecto, Pérez Triviño (2018: 122) señala que el término inglés whistleblowing "...nace de la similitud con el típico policia británico que hacia silbar (to blow) el silbato (the whistle) cuando percibia que se estaba cometiendo algún delito". Al respecto, el autor en cita refiere que:

"... la expresión difícilmente puede traducirse al castellano sin que pierda el sentido de su origen lingüístico inglés y tampoco hay término equivalente, aunque el vocablo «alertador» que se está extendiendo en los últimos años quizá sea el más adecuado. En efecto, el whistleblower ha acabado adquiriendo un significado más técnico para referirse a aquella persona que revela una información dentro de una determinada organización más o menos compleja (empresa, administración o en sentido más amplio una entidad mínimamente regulada jurídicamente), institucionalizándose la vía a través de la cual revelar la información relevante." (Pérez, 2018: 122).

En consecuencia, se reputa como denunciante de actos de corrupción a toda aquella persona que, de buena fe, denuncia a las autoridades competentes hechos relacionados con actos de corrupción. Asimismo, pueden clasificarse dependiendo de si existe o no una relación laboral entre denunciantes y denunciados: En el primer rubro encontramos a todos aquellos empleados o trabajadores (incluso aquellos que se encuentran fuera de una relación laboral tradicional) del servicio público o privado que revelen información de interés público, sobre actividades corruptas, ilegales o fraudulentas cometidas en organizaciones públicas o privadas. Por otro lado, en el segundo rubro, se incluyen las llamadas denuncias ciudadanas, las cuales provienen de personas fuera de una relación laboral que llegan a tener conocimiento de la actividad irregular al interior de las dependencias $u$ organizaciones (Nash, 2013: 6).

\footnotetext{
9 Benitez (2018: 14) afirma que la imagen del whistleblower como "alertador" es más adecuada y positiva, pues conlleva una connotación vinculada con una actuación ética y responsable, en pro del interés general y el bien común, que de alguna manera recuerda las virtudes de sus orígenes anglosajones, donde se reconoce la labor de las personas que informan sobre actos ilícitos o deshonestos.
} 
El papel de los denunciantes de actos de corrupción ha sido considerado como una de las estrategias más exitosas en el combate a la corrupción estructural, configurándose como un mecanismo que, por un lado, promueve la rendición de cuentas en el sector público y privado (Sandoval, 2010: 200), y por el otro, permite la consolidación de la democracia y el Estado de derecho. Derivado de lo cual, la inclusión progresiva de esta figura en los convenios y tratados internacionales en materia anticorrupción, así como en las estrategias nacionales de combate a la corrupción, ha sido una tendencia que cada vez cuenta con mayor fuerza. Aunado a lo anterior, y debido en gran medida a la relación que guarda la actividad de estos con el derecho a la libertad de expresión y a la información pública, la inclusión de los parámetros y principios de los derechos humanos han generado importantes avances en las obligaciones de los Estados para la protección de los denunciantes de actos de corrupción.

\subsection{Corrupción y Derechos Humanos}

Definir a la corrupción no es un tema sencillo, ya que dependiendo del lugar desde donde se mire, esta puede adoptar diversas concepciones, formas, y características. De ahí que, dependiendo de la disciplina (derecho, sociología, economía, etc.), se ponga más énfasis en ciertos elementos sobre otros para determinar su significado (Chípuli, 2019a: 140). Asimismo, se debe ser cuidadoso, ya que la corrupción puede implicar un catálogo sumamente amplio de actividades (cooptación estatal, tráfico de influencias, conflicto de intereses, negociaciones incompatibles, parcialidad, malversación de fondos, fraudes, enriquecimiento ilícito, soborno, extorsión, arreglos, colusión privada, clientelismo, nepotismo, entre muchas otras) que guardan un cierto aire de familia. Es decir, se trata de un fenómeno que abarca múltiples conductas, que van desde acepciones muy generales (vinculadas a cuestiones como la privatización del poder público, e intercambios contrarios a las normas que buscan obtener una ventaja); hasta aspectos menos abstractos y más aterrizados (como el nepotismo, el soborno, la extorsión y la prevaricación), observando una gran imprecisión que deriva de una expectativa esencialmente moral: el poder público debiera converger en el bienestar social (Vázquez, 2018).

La corrupción y los derechos humanos son conceptos que han sido profundamente estudiados, no solo por la ciencia jurídica sino por diversas disciplinas, mismas que han abonado a su comprensión desde múltiples enfoques (Chipuli, 2019b: 237). Sin embargo, es importante subrayar que no sucede lo mismo respecto de los vínculos o relaciones que existen entre la corrupción y los derechos humanos. La perspectiva que analiza los vínculos existentes entre ambos conceptos recién empieza a ser objeto de estudio a partir de los primeros años del 
siglo XXI (Nash, 2014: 25)10. Uno de los primeros trabajos realizados por un organismo internacional de protección de los derechos humanos que advierte este vínculo es el documento de trabajo presentado a la Comisión de Derechos Humanos en 2003 por la Relatora Especial Christy Mbonu, titulado "La corrupción y sus repercusiones en el disfrute de los derechos humanos, en particular los derechos económicos, sociales y culturales". Dicho documento advierte que: "el disfrute de todo tipo de derechos, ya sean económicos, sociales y culturales o civiles y políticos, está gravemente restringido por el fenómeno de la corrupción... (Por lo cual resulta necesario) contribuir a promover la transparencia, la exigencia de responsabilidades y el buen gobierno en los Estados Miembros de las Naciones Unidas que permita el disfrute de todos los derechos humanos posibles"11. Desde la emisión del citado documento, los esfuerzos por evidenciar los efectos negativos de la corrupción sobre los derechos humanos han ido en aumento, estableciendo la necesidad de que la lucha contra este fenómeno adquiera las premisas del enfoque de derechos humanos en sus planes y programas de acción.

A partir de este punto, los órganos del sistema universal de derechos humanos se han ocupado de establecer las consecuencias negativas de la corrupción ${ }^{12}$ en el disfrute de los derechos humanos, dedicando esfuerzos por definir el papel de la lucha contra la corrupción en la protección de los derechos humanos, y la creación de un entorno propicio para promoverlos. De igual forma, en el contexto del sistema interamericano de derechos humanos, es menester recordar que la Comisión Interamericana de Derechos Humanos $(\mathrm{CIDH})$ ha realizado esfuerzos similares por evidenciar las consecuencias negativas del fenómeno de la corrupción sobre los derechos humanos. Al respecto cabe citar que, desde el año 2001, la Comisión advertía: "El fenómeno de la corrupción no sólo atañe a la legitimidad de las instituciones públicas, a la sociedad, al desarrollo integral de los pueblos y a los demás aspectos de carácter más general mencionados supra, sino

\footnotetext{
${ }^{10}$ Resulta importante destacar que fue en la década de los noventas cuando empieza a gestarse la internacionalización de la lucha contra la corrupción; así como la construcción y desarrollo de los sistemas internacionales de prevención y lucha contra esta. El fin de la "época de oro" de la corrupción (particularmente a escala internacional) motivó el desarrollo de convenciones internacionales a nivel regional, interregional y en el marco del sistema de Naciones Unidas (Burneo, 2009: 333), las cuales fueron referentes para el posterior análisis por los mandatos internacionales de derechos humanos.

${ }^{11}$ Comisión de Derechos Humanos de Naciones Unidas. Subcomisión de Promoción y Protección de los Derechos Humanos. La corrupción y sus repercusiones en el disfrute de los derechos humanos, en particular los derechos económicos, sociales y culturales. Documento de trabajo presentado por la Sra. Christy Mbonu de conformidad con la decisión 2002/106 de la Subcomisión. 14 de mayo de 2003. E/CN.4/Sub.2/2003/18, párrs. 3 y 24. Disponible en: https://undocs.org/es/E/CN.4/Sub.2/2003/18

12 El Consejo de Derechos Humanos de Naciones Unidas (E/CN.4/Sub.2/2003/18) refiere que la utilización del término "consecuencias negativas en los derechos humanos" es mucho más amplio que el de "vulneración de derechos humanos", y tiene como propósito establecer que las medidas de lucha contra la corrupción deben tener en cuenta todos los tipos de consecuencias negativas derivadas de ella.
} 
que tiene además un impacto específico en el disfrute efectivo de los derechos humanos de la colectividad en general"13.

Como puede advertirse, en la actualidad existe una tendencia positiva a acercar progresivamente las agendas del combate a la corrupción y de los derechos humanos, en virtud de los beneficios que trae consigo la inclusión de cada una en sus respectivos campos de estudio. En este sentido, Nash (2013) afirma que existe un potencial especialmente promisorio en la incorporación del Derecho Internacional de los Derechos Humanos (DIDH), sobre el combate a la corrupción, ya que este puede aportar elementos y mecanismos que complementen las regulaciones nacionales, y abrir la ventana hacia la salvaguarda de los derechos humanos 14 .

\subsection{La Protección de Denunciantes de Actos de Corrupción como Derecho Humano}

En el caso de los denunciantes de actos de corrupción, la utilización del corpus iuris internacional de los derechos humanos puede evidenciar, por un lado, su conceptualización como un derecho humano, mismo que trae aparejadas obligaciones concretas para los Estados; por el otro, permite advertir obstáculos y campos de oportunidad en las estrategias nacionales implementadas para realizar su garantía. De ahi que, en el presente apartado, nos referiremos a la protección de denunciantes como un derecho humano, así como de las obligaciones y estándares internacionales que, en el caso mexicano, deben ser observados en la implementación de cualquier mecanismo de garantía de derechos.

En primer lugar, partiremos de una cuestión fundamental: ¿qué entendemos por derechos humanos? Los derechos humanos, cuya referencia se ha popularizado en México, sobre todo a partir de la reforma constitucional de junio de $2011^{15}$, representan un concepto difícil de determinar bajo una sola acepción. Los desarrollos conceptuales, así como las ideologías y perspectivas que abordan la cuestión de los derechos humanos son vastas y exceden por mucho las finalidades del presente trabajo. No obstante, una perspectiva particularmente útil para definir a los derechos humanos es la brindada por el Derecho Internacional de los

\footnotetext{
13 Comisión Interamericana de Derechos Humanos (CIDH), Tercer Informe sobre la Situación de Derechos Humanos en Paraguay. 2001. OEA. OEA/Ser./L/VII. 110. Doc. 52: Capítulo II. G. Párr. 45.

${ }^{14}$ Duran (2004: 302) afirma que el verdadero fin de la lucha contra la corrupción es el desarrollo de los derechos humanos en toda su magnitud, pues a través de la misma se busca la defensa de la democracia y la economía, los cuales representan medios para el desarrollo de la persona humana.

${ }^{15}$ Mediante la reforma constitucional de junio de 2011 en materia de derechos humanos se realizaron una serie de modificaciones tendientes a integrar el derecho internacional de los derechos humanos al sistema jurídico nacional. Particularmente, dentro del texto del artículo $1^{\circ}$ constitucional, se integraron los principios y obligaciones generales de los derechos humanos (principalmente desarrollados por el DIDH) lo que supuso un cambio de paradigma, donde estos derechos se consagrarian como la base del sistema jurídico nacional.
} 
Derechos Humanos. Bajo tal enfoque, los derechos humanos "son los derechos subjetivos necesarios para que los seres humanos puedan vivir dignamente en una sociedad organizada, que el Estado debe respetar y garantizar si no quiere comprometer su responsabilidad internacional" (Pinto, 1997: 10). Dicha concepción pone énfasis en los derechos de las personas y en las obligaciones del Estado. Estas últimas son especialmente importantes en tanto conforman exigencias de conductas en distintos planos, donde intervienen distintas autoridades (Serrano y Vázquez, 2013: 12), y que permiten conocer las acciones o abstenciones que el Estado debe llevar a cabo para la materialización de los derechos.

Con base en lo anterior, los derechos humanos se encuentran constituidos por un cumulo de obligaciones que permiten establecer un "mapa" que dote de contenido a un derecho. Estas obligaciones son reconocidas por las fuentes de hard y soft law del $\mathrm{DIDH}^{16}$, y observan diversas tipologías, no siempre claras pero que se encuentran interrelacionadas entre sí. Particularmente, en el caso mexicano, y con motivo de la citada reforma constitucional de 2011 en materia de derechos humanos, el artículo primero de la Carta Magna reconoce la existencia de cuatro obligaciones: respetar, proteger, garantizar y promover. El contenido específico de cada una de estas obligaciones variará dependiendo del derecho al que sea aplicado, por lo cual será necesario identificar, mediante un "desempaque"17, los subderechos existentes, así como el contenido obligacional que se desprende de cada uno de ellos conforme al DIDH. Asimismo, resulta importante recordar que en el caso de México, estas obligaciones internacionales provienen principalmente del Sistema de Naciones Unidas (Sistema Universal de Derechos Humanos) (SUDH) ${ }^{18}$ y

\footnotetext{
16 Tratados y convenciones internacionales, observaciones generales, informes, sentencias, resoluciones y todos aquellos insumos emanados de instancias internacionales y regionales de protección de los derechos humanos.

${ }^{17}$ La expresión "desempaque" (unpacking) es concebida a partir del marco analítico desarrollado por Paul Hunt sobre el derecho a la salud, y recuperado por Sandra Serrano y Daniel Vázquez (2013: 5153), quienes construyen una herramienta analitica que permite la operacionalización de los derechos humanos.

${ }^{18}$ La Organización de las Naciones Unidas cuenta con diversos órganos de distinta naturaleza, dentro de los cuales se puede identificar un grupo que, por abordar temas especificos con enfoque de derechos humanos o tener por objetivo la instrumentación de mecanismos de protección, constituyen el denominado Sistema Universal de Derechos Humanos (Serrano, 2016: 50). Dicho sistema se encuentra integrado por la Oficina del Alto Comisionado de las Naciones Unidas para los Derechos Humanos (OACNUDH), los órganos de tratados y los órganos de la Carta.
} 
del Sistema Interamericano de Derechos Humanos $(\mathrm{SIDH})^{19}$, con los cuales el país ha suscrito convenios con fuerza vinculante.

Ahora bien, y una vez establecido que abordaremos a los derechos humanos en términos de lo establecido por el DIDH, es menester señalar lo relativo a la protección de denunciantes. Este derecho se encuentra consagrado como un componente del derecho a la libertad de expresión, toda vez que las personas que denuncian este tipo de actos, lo realizan en ejercicio de las dos dimensiones de dicha libertad (individual y social): Por un lado, las personas tienen derecho a expresar, difundir o comunicar todo tipo de ideas, informaciones $u$ opiniones (dimensión individual); por el otro, todas las personas tienen derecho a recibir, buscar y acceder a todo tipo de expresiones, informaciones u opiniones (dimensión social) (Nash, 2013: 10). En este sentido se han pronunciado las principales fuentes de los sistemas universal (artículo 19 de la Declaración Universal de los Derechos Humanos, artículo 19 del Pacto Internacional de Derechos Civiles y Políticos), e interamericano (Artículo 13 de la Convención Americana sobre Derechos Humanos).

Asimismo, y con relación al derecho de acceso a la información pública (también adscrito como uno de los componentes centrales de la libertad de expresión), la protección de los denunciantes de actos de corrupción se ha consagrado como un ingrediente fundamental para restringir las conductas que impiden, inhiben o castigan el derecho de las personas a comunicar y denunciar actos de corrupción, o, en su caso, restringen el acceso del público a conocer sobre los mismos. Como se expresó en el caso Herrera Ulloa contra Costa Rica ${ }^{20}$ : "el control democrático, por parte de la sociedad a través de la opinión pública, fomenta la transparencia de las actividades estatales y promueve la responsabilidad de los funcionarios sobre su gestión pública, razón por la cual debe existir un margen reducido a cualquier restricción del debate político o del debate sobre cuestiones de interés público". En este sentido, los Estados deben garantizar la protección de denunciantes de actos de corrupción frente a sanciones legales, administrativas o laborales ${ }^{21}$ (OEA, 2004), así como a la imposición de normativas que prohíban o limitan la divulgación de información. En un sentido similar, e incluso con un alcance más amplio, la

\footnotetext{
${ }^{19}$ El SIDH está compuesto por dos órganos: la Comisión Interamericana de Derechos Humanos (CIDH) y la Corte Interamericana de Derechos Humanos (CoIDH). La primera, es un órgano de la Organización de Estados Americanos (OEA) creada durante la $V$ Reunión de Consulta de Ministros de Asuntos Exteriores en el año de 1959 mediante la resolución No. VIII, y cuyo estatus fue reforzado por la reforma a la Carta de la OEA que introdujo el Protocolo de Buenos Aires en 1967, y por la Convención Americana sobre Derechos Humanos (CADH) (González, 2009: 36). Por su parte, la ColDH fue establecida el 18 de julio de 1978 al entrar en vigencia la CADH, y se trata de una institución judicial autónoma cuyo objetivo es aplicar e interpretar la Convención Americana (Pelayo, 2011: 44).

${ }^{20}$ Corte Interamericana de Derechos Humanos. Caso Herrera Ulloa contra Costa Rica. 2004. Párrafo 127. Disponible en: https://www.corteidh.or.cr/docs/casos/articulos/seriec_107_esp.pdf

${ }^{21}$ Organización de Estados Americanos (OEA). Declaración Conjunta de los Relatores para la Libertad de Expresión sobre Acceso a la Información y sobre la Legislación que Regula el Secreto. 2004.
} 
Convención de Naciones Unidas contra la Corrupción (CNUCC) ha señalado, en su artículo 33, que cada Estado:

"...considerará la posibilidad de incorporar en su ordenamiento jurídico interno medidas apropiadas para proporcionar protección contra todo trato injustificado a las personas que denuncien ante las autoridades competentes, de buena fe y con motivos razonables, cualesquiera hechos relacionados con delitos tipificados con arreglo a la presente Convención".

Por su parte, la Convención Interamericana contra la Corrupción (CICC) (artículo III.8), establece la necesidad de que los Estados integren sistemas para "...proteger a los funcionarios públicos y ciudadanos particulares que denuncien de buena fe actos de corrupción, incluyendo la protección de su identidad, de conformidad con su Constitución y los principios fundamentales de su ordenamiento jurídico interno"22.

En resumen, la importancia de establecer la protección de denunciantes de actos de corrupción radica en: Primero, el valor significativo y la utilidad en la vida pública de la información que revelan estas personas; segundo, porque los denunciantes suelen enfrentar diversas formas de represalias, las cuales los ponen en situación de peligro y vulnerabilidad (Nash, 2013: 9); y tercero, la falta de protección de los denunciantes incide en los derechos fundamentales de los ciudadanos, concretamente en la libertad de expresión, pero también en otros derechos, como por ejemplo, los derechos de los medios de comunicación, los derechos laborales, el derecho a la privacidad y la vida familiar, y el derecho a una buena administración (Rodríguez-Medel, 2019: 227). De ahí que, la consagración de la protección de los denunciantes de corrupción como un derecho humano, radica primordialmente en la necesidad de establecer obligaciones a los Estados para dar adecuada garantía a los derechos humanos, en la dimensión individual (del denunciante brindándole salvaguardas ante la posible vulneración de su integridad física, psicológica, económica, laboral, etc.) y social (tutelando el interés público en un gobierno o gestión adecuada).

\footnotetext{
22 Si bien los tratados internacionales anticorrupción no son, per se, tratados sobre derechos humanos, bien vale la pena recordar que, tal y como afirma Novoa (2016: 305), estas convenciones "establecen disposiciones normativas referidas a la investigación y sanción de delitos de corrupción... (estableciendo) obligaciones para los Estados parte". Aunado a lo anterior, la autora en cita sostiene que existen en los convenios anticorrupción disposiciones que permiten inferir los vínculos con los derechos humanos, afirmando que su objeto y fin es la protección y garantía de la dignidad humana a través de la prevención y sanción de actos de corrupción (Novoa, 2016: 309). Lo anterior permite observar que la responsabilidad por violaciones a los derechos humanos surge para el Estado por su ineficacia al no investigar y/o proteger a los destinatarios de los derechos afectados por el fenómeno corrupto (Clavijo, 2012: 38).
} 
Por su parte, las obligaciones en materia de derechos humanos son aquellas que "recorren a todos y cada uno de los derechos, las relaciones entre ellos y determinan la actividad estatal... son el mapa que nos permite ubicar las conductas exigibles tanto respecto de casos particulares como en relación a la adopción de medidas y de legislación" (Serrano y Vázquez, 2013: 49 y 50). En ese sentido, y siguiendo a los autores en cita, esta dinámica permite pensar a los derechos humanos a partir de sus obligaciones, lo que hace posible establecer un "marco analítico general que examine los derechos de forma más completa" (Serrano y Vázquez, 2013: 50), operacionalizándolos y traduciéndolos en herramientas analíticas que permitan su aplicación práctica y exigibilidad. Partiendo de lo anterior, y con base en el párrafo tercero del artículo $1^{\circ}$ de la Constitución mexicana, las obligaciones pueden clasificarse en cuatro: Respeto, Protección, Garantía y Promoción. La primera obligación (respetar) es la más básica e inmediata, ya que se cumple mediante abstenciones y, a contrario sensu, se incumple por acciones, es decir, la obligación consiste en no interferir o poner en peligro los derechos. Por su parte, la obligación de proteger constituye una conducta de carácter positivo para la creación del marco jurídico y las instituciones necesarias para prevenir las violaciones, y en su caso, hacer exigibles los derechos frente a la conculcación de los mismos. Respecto de la obligación de garantía, ésta tiene por objetivo mantener el disfrute de un derecho humano y mejorarlo, de ahí que se trate de una obligación positiva que organice el aparato estatal y asegure la capacidad de disfrute del derecho mediante la remoción de obstáculos y provisión de recursos. Finalmente, la obligación de promover implica el suministro de información sobre los derechos, su ejercicio y exigibilidad, así como las tareas de sensibilización necesarias para que las personas los respeten y los promuevan (Serrano y Vázquez, 2013: 61-81). Derivado de lo anterior, las obligaciones generales inherentes al derecho humano de protección de denunciantes de actos de corrupción constan en la Tabla 1.

Como puede advertirse, las obligaciones del Estado en materia de protección de denunciantes de corrupción son vastas, y refieren un conjunto muy diverso de instrumentos de garantía. Algunas de ellas, requieren de la formulación de legislación especializada, y algunas otras de acciones concretas de política pública. Estas últimas, las abordaremos en el apartado 5 del presente trabajo. 


\section{Tabla 1. Obligaciones generales del Derecho Humano de Protección de Denunciantes de Actos de Corrupción.}

\begin{tabular}{|c|c|c|}
\hline \multicolumn{2}{|r|}{ Obligación General } & Componentes \\
\hline $\begin{array}{l}\frac{1}{\pi} \\
\frac{0}{0} \\
\frac{0}{0} \\
\stackrel{1}{\simeq}\end{array}$ & $\begin{array}{l}\text { Los Estados tienen la } \\
\text { obligación de abstenerse } \\
\text { de restringir (por acción u } \\
\text { omisión) ilegítimamente el } \\
\text { derecho a la protección de } \\
\text { denunciantes de actos de } \\
\text { corrupción (Nash, 2013: 10). }\end{array}$ & $\begin{array}{l}\text { a) No Reprime o desincentiva la denuncia. } \\
\text { b) No omite establecer salvaguardas }\end{array}$ \\
\hline \multirow[b]{2}{*}{ 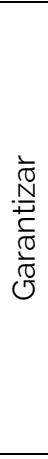 } & Adecuación normativa ${ }^{23}$ & $\begin{array}{l}\text { a) Principio de Máxima Publicidad. b) Principio de Buena Fe. c) } \\
\text { Obligación de derogar tipos penales y cláusulas que impidan la } \\
\text { denuncia. }\end{array}$ \\
\hline & $\begin{array}{l}\text { Medidas y sistemas para } \\
\text { facilitar la denuncia de } \\
\text { actos de corrupción }{ }^{24}\end{array}$ & $\begin{array}{l}\text { a) Canales amplios de denuncia, a través de un abanico } \\
\text { diversificado de instrumentos (líneas telefónicas, sitios web, } \\
\text { funcionarios especializados, oficinas de reclamos, etc.). b) } \\
\text { Autoridades adecuadas, con capacidad técnica para recibir } \\
\text { denuncias, calificarlas y conceder medidas de protección. c) } \\
\text { Procedimientos adecuados para recibir denuncias, calificarlas y } \\
\text { conceder medidas de protección. d) Mecanismos que garanticen } \\
\text { la confidencialidad y anonimato del denunciante. e) Mecanismos } \\
\text { para la participación del denunciante en el procedimiento. }\end{array}$ \\
\hline \multirow{2}{*}{ 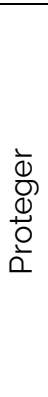 } & $\begin{array}{l}\text { Mecanismos para proteger } \\
\text { a los funcionarios públicos } \\
\text { y ciudadanos particulares } \\
\text { que denuncien actos de } \\
\text { corrupción }{ }^{25}\end{array}$ & $\begin{array}{l}\text { a) Concesión de protección por la sola denuncia. b) Amplios } \\
\text { canales de solicitud de medidas de protección. c) Protección } \\
\text { mientras subsista el peligro. d) Medidas de protección básicas: } \\
\text { asistencia legal y reserva de identidad. e) Medidas de protección } \\
\text { laboral.. f) Medidas de protección personal. }\end{array}$ \\
\hline & $\begin{array}{l}\text { Instrumentos para prevenir, } \\
\text { investigar, sancionar y } \\
\text { reparar represalias contra } \\
\text { los denunciantes }^{26}\end{array}$ & $\begin{array}{l}\text { a) Autoridades u órganos independientes para investigar } \\
\text { represalias. b) Amplia gama de medidas para evitar represalias. c) } \\
\text { Carga de la prueba al empleador. d) Investigación y sanción de } \\
\text { las represalias. }\end{array}$ \\
\hline 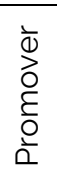 & $\begin{array}{l}\text { Promoción de la Denuncia } \\
\text { de actos de actos de } \\
\text { corrupción }{ }^{27}\end{array}$ & $\begin{array}{l}\text { a) Programas de educación pública y difusión sobre órganos y } \\
\text { mecanismos de denuncia y protección de denunciantes. b) } \\
\text { Capacitación de servidores públicos en materia de protección de } \\
\text { denunciantes. c) Programas de estímulos, premios e incentivos }\end{array}$ \\
\hline
\end{tabular}

Fuente: Elaboración Propia.

${ }^{23}$ Corte Interamericana de Derechos Humanos (CoIDH) (2006). Caso Claude Reyes y otros Vs. Chile. Sentencia de 19 de septiembre de 2006, Comisión Interamericana de Derechos Humanos Comisión Interamericana de Derechos Humanos $(\mathrm{CIDH}), 2012$. El Derecho de Acceso a la Información en el Marco Jurídico Interamericano. Segunda Edición. Washington, D.C. Organización de Estados Americanos; y Article 19, 1999. Principios sobre la libertad de información de Article 19, párr. 1.

${ }^{24}$ Artículos 8, 13, 37, 38 y 39 de la CNUCC; 7, 8, 9, 10, 11, 12, 13, 14 y 15 de la Ley Modelo para Facilitar e Incentivar la Denuncia de Actos de Corrupción y Proteger a sus Denunciantes y Testigos de la OEA.

${ }^{25}$ Artículos 32, 33 y 37 de la CNUCC; Artículo III, puntos 8, 9, 10, 11 y 12 de la CICC, Arts. 16, 17, 18 y 19 de la Ley Modelo para Facilitar e Incentivar la Denuncia de Actos de Corrupción y Proteger a sus Denunciantes y Testigos de la OEA.

${ }^{26}$ Artículo 32 de la CNUCC, 12 de la Ley Modelo para Facilitar e Incentivar la Denuncia de Actos de Corrupción y Proteger a sus Denunciantes y Testigos de la OEA; y punto 20 de los Principios Internacionales para Leyes sobre Protección de Denunciantes de Transparencia Internacional.

${ }^{27}$ Artículos $1,6,7,8,13$, y 60 de la CNUCC; 5 y 15 de la Ley Modelo para Facilitar e Incentivar la Denuncia de Actos de Corrupción y Proteger a sus Denunciantes y Testigos de la OEA. 


\section{LA POLITICA PÚBLICA EN MATERIA DE PROTECCIÓN DE DENUNCIANTES DE ACTOS DE CORRUPCIÓN EN MÉXICO (2013-2019)}

Las políticas públicas representan una forma de racionalizar la actividad pública, en la cual la acción gubernamental se encuentra orientada hacia la resolución de problemas de impacto general en un contexto determinado, a través de decisiones, estrategias y recursos del Estado. En este sentido, el enfoque de políticas públicas conlleva la necesidad de entender a lo público como aquella dimensión de la actividad humana que requiere algún tipo de intervención o regulación por parte del Estado (Parsons, 2007), y a las políticas (policy) como la capacidad del gobierno de intervenir racionalmente en la solución de problemas públicos (Del Castillo y Méndez, 2010).

De conformidad con el artículo 25 de la Constitución Política de los Estados Unidos Mexicanos, al Estado mexicano le corresponde la rectoría del desarrollo nacional, la cual se fijara con base en objetivos, metas, estrategias y prioridades, y a las que se les asignaran recursos, responsabilidades y tiempos de ejecución (Coquis, 2015; 187). En este sentido, el Plan Nacional de Desarrollo (PND) representa el principal documento de política pública en México, donde se exponen los objetivos de las distintas intervenciones públicas a nivel nacional (macro, meso y micro ${ }^{28}$ ), asimismo, establece las acciones especificas para alcanzarlos y proyecta los indicadores que permiten advertir los avances obtenidos. Dicho instrumento de planeación indica el conjunto de temas prioritarios nacionales que las acciones de gobierno se proponen abordar mediante objetivos, estrategias y líneas de acción ${ }^{29}$ (CONEVAL, 2015: 7). En resumen, el PND representa un plan que articula la filosofia, la argumentación y la posición política de las autoridades constituidas, configurándose como un plan de Estado, que se tiene que elaborar para conjuntar los recursos, las capacidades y las tecnologías del país y así definir las metas colectivas que se tienen que cumplir; esto es, representa una hoja de ruta que ordena valores, objetivos y metas que han de conseguirse en un tiempo de seis años (Uvalle, 2013: 23). En las siguientes líneas nos abocaremos a analizar, de forma general, dos Planes Nacionales de Desarrollo, y tres programas de política pública, los cuales han establecido algunas líneas de acción dirigidas a la protección de denunciantes de actos de corrupción.

\footnotetext{
${ }^{28}$ A nivel macro se encuentran los documentos más generales de la política pública como los planes sectoriales, el presupuesto de egresos, y la ley de ingresos, entre otros. Por debajo encontramos los niveles meso y micro. El primero alude a los documentos de alcance menos general, pero que no especifican todavía objetivos y metas de las unidades ejecutoras de gasto. El segundo, por su parte, contiene a todos aquellos documentos que dan lineamientos a unidades específicas, como los programas operativos anuales, los lineamientos de política pública, las reglas de operación, etc. (Salazar, 2014: 160-161).

${ }^{29}$ Consejo Nacional de Evaluación de la Política de Desarrollo Social (CONEVAL), 2015. Diagnóstico de los objetivos e indicadores de los planes derivados del Plan Nacional de Desarrollo 2013-2018. México: CONEVAL. Disponible en: https://Www.coneval.org.mx/coordinacion/IMPPS/Paginas/Diagnosticosde-Objetivos-e-Indicadores-del-PND.aspx
} 


\subsection{El Programa para un Gobierno Cercano y Moderno (2013-2018)}

El 20 de mayo de 2013, Enrique Peña Nieto, Presidente Constitucional de los Estados Unidos Mexicanos para el periodo 2012-2018, presentó el Plan Nacional de Desarrollo 2013-2018, el cual fue publicado en esa misma fecha en el Diario Oficial de la Federación. EL PND 2013-2018 tuvo como objetivo general "Llevar a México a su máximo potencial" e incluyó cinco metas nacionales: 1) "México en Paz", 2) "México Incluyente", 3) "México con Educación de Calidad", 4) "México Próspero" y 5) "México con Responsabilidad"; también puntualizó tres estrategias transversales: 1) "Democratizar la Productividad", 2) "Gobierno Cercano y Moderno" y 3) "Perspectiva de Género".

El Programa para un Gobierno Cercano y Moderno (PGCM) fue un programa de política pública macro de corte transversal que consideró un conjunto de objetivos, estrategias y acciones encaminadas a impulsar una administración pública eficiente, eficaz, innovadora y transparente, orientada a resultados y bajo los principios del gobierno abierto, así como con la capacidad tecnológica que permita la cercanía con los gobernados a través de las tecnologías de la informática y la comunicación $^{30}$.

En este tenor, y con base en el propio programa, un gobierno "cercano" significó "estar atento a las demandas y necesidades de la población y permitir el escrutinio público, de forma abierta y transparente, de las acciones de gobierno. (Implicó, además) establecer mecanismos de rendición de cuentas que permitan que los intereses de la ciudadanía se encuentren adecuadamente representados". Por su parte, un gobierno "moderno" se describió como "una clara orientación a resultados para impulsar el acercamiento con las necesidades de la población. (Utilizando) mecanismos de evaluación adecuados que midan los avances en el logro de las metas planeadas y el uso de las tecnologias de la información y comunicación $(\mathrm{TIC})^{\prime 31}$. Con estos planteamientos, señala Claudia Maldonado (2014: 2), se reafirmó la tendencia a fortalecer el acompañamiento para la mejora de la gestión contra el control interno de orden punitivo, y la necesidad de utilización de los hallazgos de la evaluación con acciones de mejora y seguimiento, así como con reasignaciones presupuestarias que permitirian premiar el desempeño.

El programa se conformó por cinco objetivos generales: 1. Impulsar un gobierno abierto para fomentar la rendición de cuentas en la Administración Pública Federal

\footnotetext{
30 Programa para un Gobierno Cercano y Moderno (2013-2018), disponible en: https://Www.gob.mx/cms/uploads/attachment/file/3114/programa-para-un-gobierno-cercano-ymoderno.pdf

${ }^{31}$ Secretaría de Hacienda y Crédito Público (SHCP). Programa para un Gobierno Cercano y Moderno. Explicación Ciudadana. México, SHCP. Disponible en: http://www.transparenciapresupuestaria.gob.mx/work/models/PTP/Presupuesto/Rendicion_de_C uentas/PGCM_VC.pdf
} 
(APF), 2. Fortalecer el presupuesto basado en resultados de la APF, 3. Optimizar el uso de los recursos en la APF, 4. Mejorar la gestión pública gubernamental en la APF; y 5. Establecer una estrategia digital nacional para acelerar la inserción de México en la sociedad de la información y del conocimiento. Para el logro de los objetivos generales antes descritos, el programa contó con 28 estrategias y 209 líneas de acción. Por el alcance del presente documento, nos centraremos en el primer objetivo (Impulsar un Gobierno Abierto que fomente la Rendición de Cuentas en la APF), el cual se fundamenta en la premisa de que la rendición de cuentas constituye el pilar central del gobierno abierto, cercano y moderno. De ahí que las estrategias y líneas de acción del programa se enfocaron en el desarrollo de algunos componentes considerados necesarios para fortalecer la rendición de cuentas en la APF. En este sentido, las estrategias (siete en total) se circunscriben a desarrollar acciones en los siguientes temas: participación ciudadana en las políticas públicas y combate a la corrupción, cultura de la legalidad, acceso a la información, transparencia de la información socialmente útil, información presupuestaria y protección de datos personales, uso de TIC's y datos abiertos; así como gestión de archivos y documentos.

Dentro de este rubro, el programa en estudio estableció la estrategia 1.2. (Promoción de una cultura de la legalidad que aumente la confianza de los mexicanos en el gobierno y prevenga la corrupción), la cual contempló tres acciones concretas en la materia:

Las acciones 1.2.7 (fortalecer los canales de denuncia de servidores públicos para que sean confiables y efectivos), 1.2.8 (construir un sistema para la protección a denunciantes, víctimas y testigos de conductas ilícitas en que incurran los servidores públicos) y 1.2.9 (Fortalecer incentivos legales y esquemas de autorregulación para que el sector privado denuncie incidentes de corrupción). La implementación de estas acciones correspondia a la Secretaría de la Función Pública (SFP) ${ }^{32}$. En el primer caso (acción 1.2.7), y con base en el Plan Estratégico 2016-2018 de la Secretaría de la Función Pública, se creó el Sistema Integral de Quejas y Denuncias Ciudadanas, el cual si bien no se encontraba vinculado en sentido estricto con la protección de denunciantes, si estableció algunas medidas para la recepción de quejas y denuncias anónimas sobre actos irregulares cometidos por servidores públicos, las cuales cumplieron en cierta medida con el objetivo planteado por la línea de acción. Por su parte, y respecto de las acciones 1.2.8 y 1.2.9, no hay evidencia que revele la existencia de acciones concretas en materia de protección de denunciantes ni de incentivos para la denuncia en el

\footnotetext{
${ }^{32}$ Conforme a los artículos 26 y 37 de la Ley Orgánica de la Administración Pública Federal, la Secretaría de la Función Pública es una dependencia del Poder Ejecutivo Federal encargada, entre muchas cosas, de coordinar el sistema de control interno y de evaluación de la gestión en la APF, así como implementar las acciones del Sistema Nacional Anticorrupción, entre las cuales se encuentra conocer e investigar las conductas de servidores públicos que puedan constituir responsabilidades administrativas.
} 
sector privado por parte de la Secretaría de la Función Pública, o por alguno de los órganos de la APF. De igual forma, ni el PGCM, ni sus bases de operación, establecieron indicadores que permitieran dar cuenta de las medidas adoptadas, o los avances en el cumplimiento del objetivo propuesto.

Derivado de lo anterior, se observa una incidencia mínima, o más bien simbólica, de los estándares en materia de protección de denunciantes en el diseño de la política pública. Aunque el programa estableció líneas de acción para este fin, dicha cuestión quedo desdibujada por la falta de acción concretas en la implementación. No obstante esto, es necesario señalar que con la reforma constitucional en materia anticorrupción de 2015 se dieron algunos avances legislativos en la materia, de los cuales se destacan los siguientes:

- El 7 de mayo de 2015 se publicó en el Diario Oficial de la Federación el decreto por el cual se reformaron 14 preceptos constitucionales. El objetivo de la reforma fue fortalecer la confianza de los ciudadanos en las instituciones nacionales, a través de un marco de promoción de la legalidad, las buenas prácticas, la transparencia y la rendición de cuentas; así como de un renovado marco normativo que redefiniera las facultades de las autoridades y entes relacionados con el sistema anticorrupción, y dotara de eficacia a los procedimientos de sanción de servidores públicos y particulares por actos de corrupción, tanto por la vía penal como por la vía administrativa (Guerrero, 2018: 11)

- La expedición de la Ley General del Sistema Nacional Anticorrupción, publicada el 18 de julio de 2016, proporcionó el marco jurídico el nuevo sistema de responsabilidades de los servidores públicos en México, así como a la Plataforma Digital Nacional, la cual posteriormente contemplaría en su diseño un sistema de denuncias públicas de faltas administrativas y hechos de corrupción.

- La reforma al Código Penal Federal de misma fecha, por la cual se estableció el delito de intimidación (fracción I del artículo $219^{33}$ ), el cual funge como mecanismo disuasivo para el ejercicio de represalias contra denunciantes de actos de corrupción.

- En julio de 2017, se expide la Ley General de Responsabilidades Administrativas de los Servidores Públicos (LGRASP), en la cual se consagra que "... los Servidores Públicos que denuncien una Falta administrativa grave o Faltas de particulares, o sean testigos en el procedimiento, podrán solicitar medidas de protección que

33 "Comete el delito de Intimidación: (...) l.- El servidor público que por sí, o por interpósita persona, utilizando la violencia física o moral, inhiba o intimide a cualquier persona para evitar que ésta o un tercero denuncie, formule querella o aporte información relativa a la presunta comisión de una conducta sancionada por la Legislación Penal o por la Ley General de Responsabilidades Administrativas" (Art. 219 del Código Penal Federal). 
resulten razonables" (Artículo 64 LGRASP). Asimismo, contempló la figura de denuncia anónima, y la confidencialidad de la identidad de los denunciantes.

Como puede advertirse, el desarrollo legislativo fue vasto en los años posteriores a la implementación del programa en estudio, integrando contenidos que rompian con las inercias imperantes en el sistema anticorrupción. Esta tendencia se volvió más fuerte hacia finales de sexenio, sin embargo, la materialización de acciones de política pública concretas, que derivasen en la persecución y sanción efectiva de actos de corrupción, fue la gran deuda a saldar por el gobierno de Peña Nieto.

\subsection{Programa Nacional de Combate a la Corrupción y a la Impunidad, y de Mejora de la Gestión Pública (2019-2024)}

Con el triunfo de Morena en las urnas, Andrés Manuel López Obrador asume la presidencia de la República mexicana el $1^{\circ}$ de diciembre de 2018. En su discurso de toma de protesta, el tema de la corrupción ocupó un lugar destacado, de donde se pueden extraer algunas frases:

"Con apego a mis convicciones y en uso de mis facultades, me comprometo a no robar y a no permitir que nadie se aproveche de su cargo o posición para sustraer bienes del erario o hacer negocios al amparo del poder público", "El gobierno ya no será un facilitador para el saqueo, como ha venido sucediendo. Ya el gobierno no va a ser un comité al servicio de una minoría rapaz", "La crisis de México se originó no solo por el fracaso por el modelo económico neoliberal aplicado en los últimos 36 años de gobierno, sino por el predominio de la más inmunda corrupción pública y privada" ${ }^{34}$.

Con base en lo anterior, el 12 de julio de 2019 se publica en el Diario Oficial de la Federación el Plan Nacional de Desarrollo 2019-2024. Dicho documento propone una política nacional de desarrollo basada en doce principios rectores: 1. "Honradez y honestidad", 2. "No al gobierno rico con pueblo pobre", 3. "Al margen de la ley, nada; por encima de la ley, nadie", 4. "Economía para el bienestar", 5. "No dejar a nadie atrás, no dejar a nadie fuera", 6. "El mercado no sustituye al Estado", 7. "Por el bien de todos, primero los pobres", 8. "No puede haber paz sin justicia", 9. "El respeto al derecho ajeno es la paz", 10. "No más migración por hambre o violencia", 11. "Democracia significa el poder del pueblo"; y 12. "Ética, libertad y confianza". Los cuales, de acuerdo con el propio documento, "son los puntos centrales del nuevo consenso nacional"35 Asimismo, el PND establece tres ejes centrales de la política pública nacional para el periodo 2019-2024: i. Política y Gobierno (Justicia y Estado

${ }^{34}$ BBC (1 de diciembre de 2018). Toma de protesta de AMLO: 5 frases de López Obrador en su primer mensaje como presidente de México. BBC. Disponible en: https://www.bbc.com/mundo/noticiasamerica-latina-46415477

35 Plan Nacional de Desarrollo 2019-2024. Disponible en: https://www.dof.gob.mx/nota_detalle.php?codigo=5565599\&fecha=12/07/2019 
de Derecho), ii. Política Social (Bienestar); y iii. Economía (Desarrollo Económico), los cuales agrupan los problemas públicos identificados en el diagnóstico, y establecen objetivos y resultados especificos para la implementación de cada uno. Finalmente, el PND contempla tres ejes transversales: a) Igualdad de género, no discriminación e inclusión, b) Combate a la corrupción y mejora de la gestión pública; y c) Territorio y Desarrollo sostenible.

La corrupción, además de ser un tópico recurrente dentro del PND, constituye una de las problemáticas más importantes dentro de la política nacional, de ahí que, en el primer eje general (Justicia y Estado de Derecho), aparece la erradicación de la corrupción como uno de los objetivos prioritarios a desarrollar durante la gestión de la actual administración pública. En este sentido, el Plan señala:

“...erradicar la corrupción del sector público es uno de los objetivos centrales del sexenio en curso. Con este propósito, el Poder Ejecutivo Federal pondrá en juego todas sus facultades legales a fin de asegurar que ningún servidor público pueda beneficiarse del cargo que ostente, sea del nivel que sea, salvo en lo que se refiere a la retribución legítima y razonable por su trabajo. Lo anterior significa un combate total y frontal a las prácticas del desvio de recursos, la concesión de beneficios a terceros a cambio de gratificaciones, la extorsión a personas físicas o morales, el tráfico de influencias, el amiguismo, el compadrazgo, la exención de obligaciones y de trámites y el aprovechamiento del cargo o función para lograr cualquier beneficio personal o de grupo"36.

Por su parte, una innovación relevante, respecto de planes anteriores, lo constituye la incorporación del combate a la corrupción como un elemento transversal de la política pública nacional, que conlleva la necesidad de garantizar la eficiencia en la administración pública, la reducción de espacios de discrecionalidad y riesgos en la aplicación de recursos. Tarea que se encuentra vinculada con lo establecido por el artículo 134 de la Constitución Política de los Estados Unidos Mexicanos, donde se establece el principio general por el cual los recursos económicos de la federación deberán aplicarse con eficacia, eficiencia, economía, transparencia y honradez.

Derivado de lo antes expuesto, el 30 de agosto de 2019 fue publicado en el Diario Oficial de la Federación el Programa Nacional de Combate a la Corrupción y a la Impunidad, y de Mejora de las Gestión Pública (PNCCIMGP) 2019-2024. Dicho programa se desprende del primer apartado del Eje General 1, con el objetivo de afianzar las acciones de la APF en el combate a la corrupción y la impunidad en el ámbito administrativo, de conformidad con lo señalado por el PND 2019-2024, la Ley General del Sistema Nacional Anticorrupción, y la Ley General de Responsabilidades Administrativas de los Servidores Públicos; así como dar

${ }^{36}$ Plan Nacional de Desarrollo, 2019, pág. 14. 
cumplimiento a los compromisos asumidos por el Estado mexicano en la suscripción de la Convención de las Naciones Unidas contra la Corrupción, la Convención Interamericana contra la Corrupción, y la Convención para Combatir el Cohecho de Servidores Públicos Extranjeros en Transacciones Comerciales Internacionales de la Organización para la Cooperación y Desarrollo Económicos (OCDE).

Para el logro de sus propósitos, el programa contempla cinco objetivos prioritarios: 1. Combatir frontalmente las causas y efectos de la corrupción, 2. Combatir los niveles de impunidad administrativa en el Gobierno Federal, 3. Promover la eficiencia y la eficacia de la gestión pública, 4. Promover la profesionalización y la gestión eficiente de los recursos humanos de la Administración Pública Federal; y 5. Promover el uso eficiente y responsable de los bienes del Estado mexicano. Para efectos del presente trabajo nos referiremos al objetivo prioritario número 1, pues en este se dispone que "...se alentará la participación y protección de alertadores ciudadanos y denunciantes" ${ }^{\prime 37}$, cuestión que motiva la incorporación de una estrategia prioritaria (señalada con el numero 1.5), la cual busca impulsar y operar un sistema de ciudadanos alertadores internos y externos de la corrupción, que permita captar actos graves de corrupción, asi como los relacionados con hostigamiento, acoso sexual y violaciones a los derechos humanos, garantizando la confidencialidad de la información que se proporciona, otorgando medidas de protección ante represalias y estableciendo acciones de seguimiento para el desahogo de la alerta. Las acciones específicas descritas por el programa de política pública son cinco, y se citan a continuación:

37 Programa Nacional de Combate a la Corrupción y a la Impunidad, y de Mejora de las Gestión Pública, pág.

$7 . \quad$ Disponible https://Www.dof.gob.mx/nota_detalle.php?codigo=5570984\&fecha=30/08/2019 


\section{Tabla 2. Estrategia Prioritaria 1.5: Impulsar y operar un Sistema de Ciudadanos Alertadores Internos y Externos de la Corrupción para captar actos graves de corrupción.}

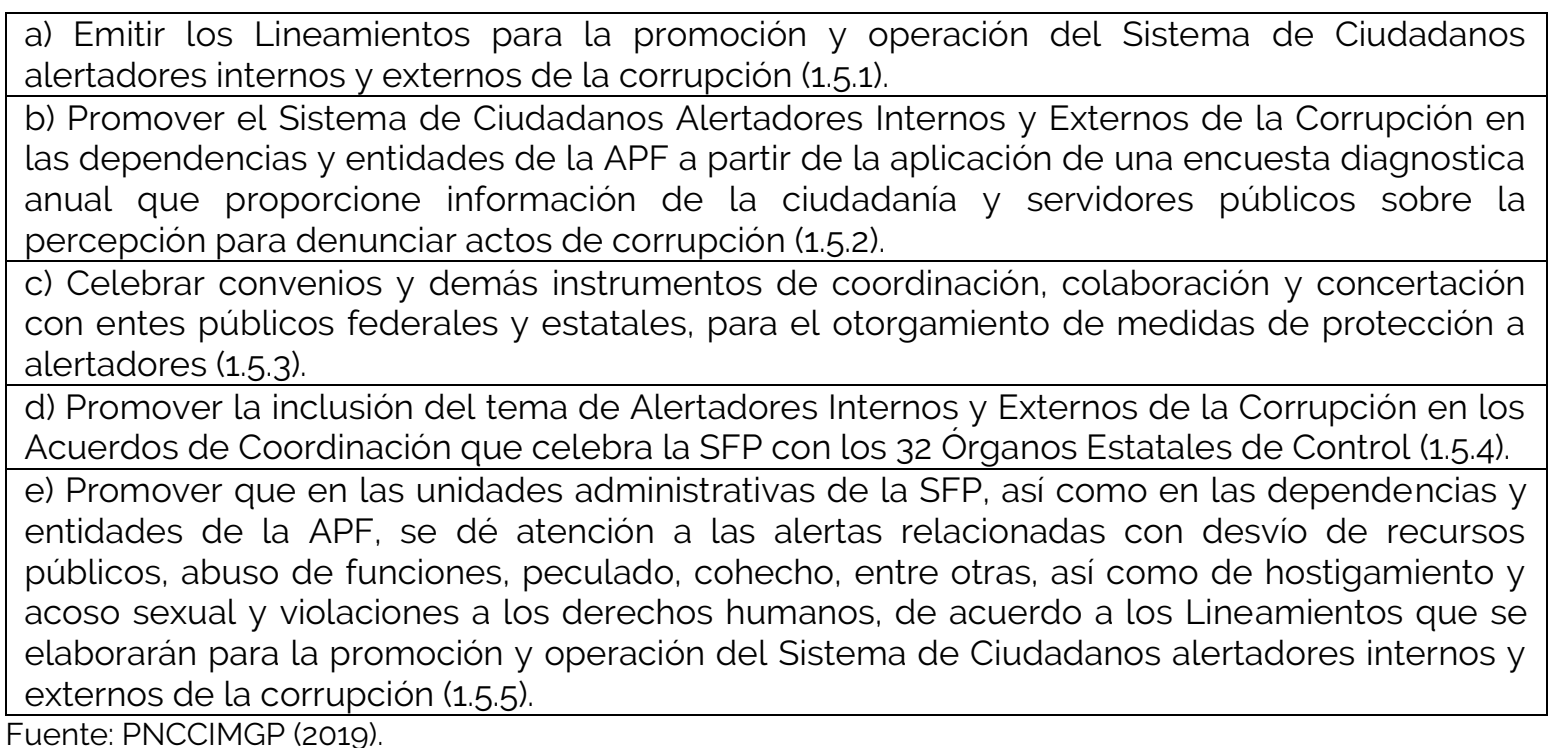

A diferencia del PGCM 2013-2018, el programa en estudio resulta ser más específico en la necesidad de establecer mecanismos de protección de denunciantes (alertadores en términos del programa), a tal punto de proponer acciones específicas para la creación de un Sistema de Ciudadanos Alertadores Internos y Externos de Corrupción. No obstante, y con base en las acciones estratégicas antes citadas, la protección de denunciantes queda sujeta a la normatividad que se emita para regular y operar el Sistema de Alertadores. Más allá, el programa resulta omiso en establecer acciones de protección diferentes de la confidencialidad en la "alerta". Si bien en el diagnostico refiere el problema de la impunidad, derivado de la falta de confianza en las instituciones encargadas de la investigación y sanción de actos de corrupción, se omite en todo caso la necesidad de generar garantías adecuadas a los denunciantes, sobre todo frente a un contexto marcadamente tolerante a la corrupción. De alguna manera, tales omisiones son subsanadas en algunos aspectos generales con la expedición posterior de los Lineamientos para la Promoción y Operación del Sistema de Ciudadanos Alertadores Internos y Externos de la Corrupción, los cuales establecen una política pública de nivel micro, a cargo de la Secretaría de la Función Pública, que complementan el mandato del presente programa.

Fuera de la citada estrategia, el programa advierte algunos elementos vinculados con los procedimientos de denuncia (acción 1.1.9); así como respecto de la promoción, educación y capacitación en materia de protección de denunciantes (acciones 1.1.3, 1.1.5, 2.1.1, 2.1.2. 2.1.10, 2.2.1 y 2.2.8), más no se abocan de forma exclusiva a esta cuestión. 


\subsection{Lineamientos para la Promoción y Operación del Sistema de Ciudadanos Alertadores Internos y Externos de la Corrupción}

El 6 de septiembre de 2019, la Secretaría de la Función Pública emite un Acuerdo por el cual se establecen los Lineamientos para la Promoción y Operación del Sistema de Ciudadanos Alertadores Internos y Externos de la Corrupción (LPOSCAEIC) $^{38}$, el cual busca instrumentar lo relativo al sistema de alertadores enunciado en la estrategia prioritaria 1.5 del Programa Nacional de Combate a la Corrupción y a la Impunidad, y de Mejora de las Gestión Pública 2019-2024. Asimismo, se fundamenta en la Ley General de Responsabilidades Administrativas de los Servidores Públicos (artículo 3, fracción IX, y 64) por cuanto hace a las medidas para la denuncia de actos $u$ omisiones que pueden constituir faltas y sanciones administrativas, y la solicitud de medidas de protección a los denunciantes, así como en las Convenciones Interamericana y de Naciones Unidas en materia anticorrupción.

De acuerdo con los lineamientos, el Sistema involucra todo un conjunto de procedimientos y mecanismos que permiten gestionar las "alertas" ${ }^{\text {"9 }}$ de los ciudadanos internos y externos de la corrupción ${ }^{40}$, así como garantizar la existencia de procedimientos que garanticen la confidencialidad, integridad y goce pleno de sus derechos. En este sentido, los citados lineamientos consagran tres elementos de fundamental importancia:

a) Un catálogo de derechos inherentes a los alertadores. El numeral sexto de los Lineamientos señala que los alertadores tendrán los siguientes derechos: Acceso a un mecanismo seguro de comunicación, el cual debe contar con garantías para la protección de la información y el anonimato. Protección de su integridad, específicamente para que la identidad no sea revelada, Derecho a solicitar y recibir medidas de protección contra represalias, Derecho a renunciar al anonimato; y Derecho a la información sobre el estado del procedimiento de alerta.

b) Una plataforma tecnológica de alerta. Administrada por la Secretaría de la Función Pública, la cual se encargara de substanciar el procedimiento de atención de alertas, así como de establecer la procedencia o improcedencia de la misma. Dicho procedimiento debe garantizar el anonimato, la seguridad, y la protección de

\footnotetext{
${ }^{38}$ Acuerdo por el que se establecen los Lineamientos para la Promoción y Operación del Sistema de Ciudadanos Alertadores Internos y Externos de la Corrupción. Disponible en: https://alertadores.funcionpublica.gob.mx/documentos/Lineamientos_alertadores_DOF_6_Sep.pdf

39 Las "alertas" constituyen comunicaciones previas al inicio del procedimiento administrativo, que proporciona información sobre actos graves de corrupción, violaciones a derechos humanos, hostigamiento y acoso sexual (LPOSCAIEC, 2019: numeral Segundo).

${ }^{40}$ Los ciudadanos alertadores se clasifican en dos tipos: internos y externos. Los primeros refieren a los funcionarios y servidores públicos adscritos a cualquier órgano, dependencia o instancia estatal. Los segundos, involucran a todos aquellos ciudadanos que no ostentan un empleo, cargo o comisión en los órganos gubernamentales (LPOSCAIEC, 2019: numeral Segundo).
} 
la información personal del alertador en bases de datos y metadatos (LPOSCAIEC, 2019: numeral decimo).

c) Medidas de protección al alertador. Las cuales pueden ser solicitadas por el alertador a través de la plataforma, siempre y cuando señale los riesgos que advierte. Dichas medidas tienen un carácter tutelar y su finalidad es brindar asistencia y acompañamiento, o garantizar el goce de sus derechos frente a represalias y menoscabos (LPOSCAIEC, 2019: numeral décimo octavo). Entre las medidas contempladas se encuentran: Atención psicológica o médica, aquellas que permitan que no se le sancione, asistencia en procedimientos laborales o civiles que sean consecuencia de la denuncia, reubicación laboral; y licencia temporal, con goce de sueldo.

De lo anterior resulta evidente que, los lineamientos en estudio, permiten la construcción de un mecanismo que facilita la denuncia a través de medios electrónicos, estableciendo incluso instrumentos y procedimientos para acceder a las medidas de protección de denunciantes, mismas que se circunscriben a la asistencia legal, la atención médica, o medidas extraordinarias de carácter administrativo.

Sin duda, tanto el PNCCIMGP, como los Lineamientos, han marcado un avance significativo respecto de la situación guardada en la política pública del sexenio 2012-2018. Como se vio, el PGCM proyectó un importante precedente al visibilizar la necesidad de establecer acciones públicas en materia de protección de denunciantes de actos de corrupción. Sin embargo, la omisión en la implementación de estrategias concretas puso en entredicho el propósito inicial del programa. En el caso de la política pública vigente, al menos puede apreciarse un esfuerzo contundente por pasar del combate a la corrupción como discurso, a la realización de acciones concretas en el marco de la política pública.

\section{POLÍTICA PÚBLICA Y PROTECCIÓN DE DENUNCIANTES DE ACTOS DE CORRUPCIÓN EN MÉXICO}

Pisarello (2007: 112) establece que la defensa de los derechos humanos requiere de un sistema de garantías "multinivel" que posibilite la tutela de los derechos humanos a través de vias "más participativas", que escapen a la tentación de reducirlos a meras cuestiones de justiciabilidad ante los tribunales y órganos del poder judicial, y que comprometa a los diferentes actores estatales y sociales en dicha tarea. En este sentido, las políticas públicas han generado un interés fundamental, ya que pueden constituirse como respuestas institucionales para materializar muchos de los compromisos y obligaciones en materia de derechos humanos que han adoptado los Estados a través de los tratados y convenciones internacionales. De tal forma que las políticas públicas se vislumbran como medios de satisfacción de derechos, y no sólo como mecanismos para la solución de 
problemas y demandas insatisfechas (Salazar, 2014), reconociendo a las personas como titulares de derechos, empoderándolas para exigir o demandar acciones concretas del Estado, a través de un marco de obligaciones consagradas por el $\mathrm{DIDH}$.

Las obligaciones en materia de protección de denunciantes, como se apuntó en el apartado 3, son diversas y motivan la acción del Estado a través de múltiples vías para la garantía efectiva del derecho en cuestión. Las políticas públicas representan un mecanismo de exigibilidad de los derechos, las cuales, mediante un conjunto de objetivos, acciones y estrategias, materializan los compromisos adoptados por los Estados respecto de los denunciantes de actos de corrupción. De ahí que, con base en el marco de obligaciones presentado líneas arriba, en la página siguiente se expone la tabla 3 que refiere el cumplimiento de las mismas por parte de las políticas públicas analizadas anteriormente ${ }^{41}$.

Como puede advertirse, la tabla se encuentra construida por dieciocho elementos, los cuales se confrontan con el contenido de los programas de política pública previamente analizados. En el caso del Programa para un Gobierno Cercano y Moderno (2013-2018), se visibiliza la protección de denunciantes, pero solo aborda tres elementos del marco de obligaciones. El segundo programa, establece estrategias y acciones concretas respecto de los canales y los procedimientos, así como aspectos de difusión y capacitación. Empero, deja muchas obligaciones abiertas a las directrices que el órgano encargado de la implementación (la SFP) realice en el marco de sus competencias. Finalmente, los Lineamientos, complementan en gran medida el PNCCIMGP, mostrando un avance significativo en el cumplimiento de las obligaciones internacionales, principalmente respecto de las medidas concretas de protección y los procedimientos a seguir. No obstante, deja fuera siete rubros, muchos de ellos en el marco de las acciones contra represalias.

\footnotetext{
${ }^{41}$ Se omitieron de la tabla las obligaciones de respeto y adecuación normativa, en virtud de que las primeras conllevan obligaciones negativas, de abstención, cuya naturaleza se encuentra fuera de la implementación de acciones concretas de política pública. Por su parte, la adecuación normativa, refiere a elementos relativos a otro mecanismo de exigibilidad: la legislación, que no es objeto del presente documento.
} 


\section{Tabla 3. Cuadro Comparativo de Cumplimiento de Obligaciones en Materia de Protección de Denunciantes de Actos de Corrupción por las Políticas Públicas (2013-2019)}

\begin{tabular}{|c|c|c|c|}
\hline Componentes & PGCM & PNCCIMGP & LPOSCAIEC \\
\hline $\begin{array}{l}\text { Canales amplios de denuncia, a través de un } \\
\text { abanico diversificado de instrumentos (líneas } \\
\text { telefónicas, sitios web, funcionarios } \\
\text { especializados, oficinas de reclamos, etc.) }\end{array}$ & $\begin{array}{l}\text { Acción } \\
1.2 .7\end{array}$ & $\begin{array}{l}\text { Estrategia } \\
\quad 1.5\end{array}$ & $\begin{array}{l}\text { Sección III, numeral } \\
\text { Decimo }\end{array}$ \\
\hline $\begin{array}{l}\text { Autoridades adecuadas, con capacidad técnica } \\
\text { para recibir denuncias, calificarlas y conceder } \\
\text { medidas de protección. }\end{array}$ & $\begin{array}{l}\text { Sin } \\
\text { acciones }\end{array}$ & Sin acciones & $\begin{array}{l}\text { Sección III, numeral } \\
\text { Décimo Quinto }\end{array}$ \\
\hline $\begin{array}{l}\text { Procedimientos adecuados para recibir } \\
\text { denuncias, calificarlas y conceder medidas de } \\
\text { protección. }\end{array}$ & $\begin{array}{l}\text { Sin } \\
\text { acciones }\end{array}$ & $\begin{array}{l}\text { Acción 1.1.9, } \\
\text { Estrategia } \\
1.5\end{array}$ & $\begin{array}{c}\text { Sección III, } \\
\text { numerales } \\
\text { Duodécimo al } \\
\text { Décimo séptimo. }\end{array}$ \\
\hline $\begin{array}{l}\text { Mecanismos que garanticen la confidencialidad y } \\
\text { anonimato del denunciante. }\end{array}$ & $\begin{array}{c}\text { Sin } \\
\text { acciones }\end{array}$ & $\begin{array}{l}\text { Estrategia } \\
\quad 1.5\end{array}$ & $\begin{array}{l}\text { Sección III, numeral } \\
\text { Undécimo }\end{array}$ \\
\hline $\begin{array}{l}\text { Mecanismos para la participación del denunciante } \\
\text { en el procedimiento }\end{array}$ & $\begin{array}{c}\text { Sin } \\
\text { acciones }\end{array}$ & Sin acciones & $\begin{array}{l}\text { Sección III, numeral } \\
\text { Duodécimo }\end{array}$ \\
\hline Concesión de protección por la sola denuncia. & $\begin{array}{c}\text { Sin } \\
\text { acciones }\end{array}$ & Sin acciones & Sin acciones \\
\hline $\begin{array}{l}\text { Amplios canales de solicitud de medidas de } \\
\text { protección }\end{array}$ & $\begin{array}{c}\text { Sin } \\
\text { acciones }\end{array}$ & Sin acciones & $\begin{array}{l}\text { Sección IV, numeral } \\
\text { Décimo Octavo }\end{array}$ \\
\hline Protección mientras subsista el peligro. & $\begin{array}{c}\text { Sin } \\
\text { acciones }\end{array}$ & Sin acciones & $\begin{array}{c}\text { Sección IV, numeral } \\
\text { Vigésimo }\end{array}$ \\
\hline $\begin{array}{l}\text { Medidas de protección básicas: asistencia legal y } \\
\text { reserva de identidad. }\end{array}$ & $\begin{array}{c}\text { Acción } \\
1.2 .8 \\
\end{array}$ & $\begin{array}{c}\text { Estrategia } \\
1.5\end{array}$ & $\begin{array}{l}\text { Sección IV, numeral } \\
\text { Décimo Noveno }\end{array}$ \\
\hline Medidas de protección laboral. & $\begin{array}{c}\text { Sin } \\
\text { acciones }\end{array}$ & Sin acciones & $\begin{array}{l}\text { Sección IV, numeral } \\
\text { Décimo Noveno }\end{array}$ \\
\hline Medidas de protección personal. & $\begin{array}{c}\text { Sin } \\
\text { acciones }\end{array}$ & Sin acciones & $\begin{array}{l}\text { Sección IV, numeral } \\
\text { Décimo Noveno }\end{array}$ \\
\hline $\begin{array}{l}\text { Autoridades u órganos independientes para } \\
\text { investigar represalias }\end{array}$ & $\begin{array}{l}\operatorname{Sin} \\
\text { acciones }\end{array}$ & Sin acciones & Sin acciones \\
\hline Amplia gama de medidas para evitar represalias. & $\begin{array}{c}\text { Sin } \\
\text { acciones }\end{array}$ & $\begin{array}{c}\text { Estrategia } \\
1.5\end{array}$ & Sin acciones \\
\hline Carga de la prueba al empleador & $\begin{array}{c}\text { Sin } \\
\text { acciones }\end{array}$ & Sin acciones & Sin acciones \\
\hline Investigación y sanción de las represalias. & $\begin{array}{c}\text { Sin } \\
\text { acciones }\end{array}$ & Sin acciones & Sin acciones \\
\hline $\begin{array}{l}\text { Programas de educación pública y difusión sobre } \\
\text { órganos y mecanismos de denuncia y protección } \\
\text { de denunciantes. }\end{array}$ & $\begin{array}{l}\text { Sin } \\
\text { acciones }\end{array}$ & $\begin{array}{l}1.1 .3,1.1 .5 \\
1.5 .2\end{array}$ & Sin acciones \\
\hline $\begin{array}{l}\text { Capacitación de servidores públicos en materia } \\
\text { de protección de denunciantes }\end{array}$ & $\begin{array}{l}\operatorname{Sin} \\
\text { acciones }\end{array}$ & $\begin{array}{c}1.1 .3,1.1 .5 \\
1.5 .2,1.5 .5 \\
2.1 .1,2.1 .2 \\
2.1 .10,2.2 .1 \\
2.2 .8 \\
\end{array}$ & $\begin{array}{l}\text { Sección VII, numeral } \\
\text { Vigésimo octavo }\end{array}$ \\
\hline Programas de estímulos, premios e incentivos & $\begin{array}{c}\text { Acción } \\
1.2 .9 \\
\end{array}$ & Sin acciones & Sin acciones \\
\hline
\end{tabular}

Fuente: Elaboración Propia. 


\section{CONCLUSIONES}

México afronta un problema grave de corrupción, el cual no ha sido abordado de forma eficaz. Más allá de la legislación, la cual muestra un avance importante desde la reforma constitucional de 2015, la implementación de estrategias, objetivos y acciones de política pública han estado ausentes. Sin duda, un importante mecanismo que ha quedado fuera ha sido la protección de denunciantes de actos de corrupción, la cual es necesaria para abatir este fenómeno. La relación que esta protección tiene con la libertad de expresión, así como la cada vez mayor relación entre la agenda anticorrupción y de derechos humanos, han llevado a considerarla como un derecho humano, y como tal, bajo una noción proveniente del DIDH, contiene un marco de obligaciones que el Estado debe observar y cumplir.

Estas obligaciones sirvieron de marco de referencia para examinar tres programas de política pública vigentes en México durante el periodo 2013-2019, evidenciando una progresiva inclusión de la protección de denunciantes en el diseño de la politica nacional. No obstante, quedan espacios por llenar, y obligaciones por cumplir, y es responsabilidad del Estado mexicano llevar a cabo un replanteamiento de las estrategias necesarias, no solo para combatir eficazmente la corrupción, sino para proteger a aquellos que ponen en riesgo su integridad, su trabajo y a sus familias con la finalidad de contribuir con esta lucha.

\section{BIBLIOGRAFÍA}

Banisar, D. 2011. "Whistleblowing: International Standars and Developments" en Sandoval, I., Corruption and Transparency: Debating the frontiers between State, Market and Society, Washington: UNAM-World Bank -Institute for Social Research. Disponible en: https://papers.ssrn.com/sol3/papers.cfm?abstract_id=1753180

Bautista, O.D., 2017. Cien años de corrupción en México a partir de la era postrevolucionaria 1917-2017. México: Poder Legislativo del Estado de México.

Benitez, E. 2018. "El Control Externo y el whistleblowing (canales de denuncia)", Revista Española de Control Externo, 59: 11-42. Disponible en: https://dialnet.unirioja.es/servlet/ejemplar?codigo=524777\&info=open_link_eje mplar

Burneo, J. 2009. "Corrupción y Derecho Internacional de los derechos humanos", Derecho PUCP: Revista de la Facultad de Derecho, 63: 333-347. Disponible en: https://dialnet.unirioja.es/descarga/articulo/5085242.pdf 
Coquis, F.J., 2015. "Sistema Nacional de Planeación", en Fernández Ruiz, J., La Constitución y el Derecho Administrativo. México: UNAM, 187- 204.

Chípuli Castillo, A.M., 2019a. "Corrupción y Derechos Humanos (Reseña de Vázquez, L. D., 2018. Corrupción y Derechos Humanos: ¿por dónde comenzar la estrategia anticorrupción?)", Letras Juridicas: Revista Multidisciplinar del Centro de Estudios sobre Derecho, Globalización y Seguridad de la Universidad Veracruzana, 39: 237240. Disponible en: http://www.letrasjuridicas.com.mx/wpcontent/uploads/2019/02/Res1-39.pdf

Chípuli Castillo, A.M., 2019b. "Corrupción y Derechos Humanos: Una Visión desde el Ámbito Municipal", en Huerta Barrera, T.R. (Coord.), 500 Años del Municipio en México: Perspectivas Multidisciplinarias. México: Universidad de Guanajuato, 138159. Disponible en: https://www.ugto.mx/campusgto/images/2019/pdf/500anos-del-municipio-en-Mexico.pdf

Chipuli Castillo, A.M., 2017. Breve Historia de la Responsabilidad de los Servidores Públicos en México. México: Universidad de Xalapa.

Clavijo, A.S. 2012. "Actos de corrupción como violación a los derechos humanos", Saber, Ciencia y Libertad, 7: 35-45. Disponible en: https://dialnet.unirioja.es/descarga/articulo/5109378.pdf

Del Castillo, G. y Méndez, I., 2010. Introducción a la teoría de las politicas públicas. México: Flacso-México.

Duran, A. 2004. "Derechos humanos y corrupción administrativa", Anuario da Facultade de Dereito da Universidade da Coruña, 8: 299-310. Disponible en: https://dialnet.unirioja.es/servlet/articulo?codigo=975297\&orden=312106\&info=li nk

González Morales, F., 2009. "La Comisión Interamericana de Derechos Humanos: antecedentes, funciones y otros aspectos", Anuario de Derechos Humanos, 5: 3557.

Guerrero, C.G. 2018. "Retos en México en materia de protección de denunciantes, con relación a estándares internacionales", Revista Internacional de Transparencia e Integridad, 8: 1-18. Disponible en: https://dialnet.unirioja.es/servlet/articulo?codigo=6774693\&orden=0\&info=link

Maldonado Trujillo, C. V., 2014. "Gobierno Cercano y Moderno: Una mirada crítica", en Memoria del XIX Congreso Internacional del CLAD sobre la Reforma del Estado y de la Administración Pública. Quito: CLAD. Disponible en: http://siare.clad.org/fulltext/0077421.pdf 
Nash, C., et al, 2014. Corrupción y Derechos Humanos: Una mirada desde la jurisprudencia de las Corte Interamericana de Derechos Humanos. Chile: Centro de Derechos Humanos de la Facultad de Derecho.

Nash, C. et al, 2013. Guía para la utilización del Sistema Interamericano de Derechos Humanos en la protección de los denunciantes de actos de corrupción. Chile: Centro de Derechos Humanos de la Facultad de Derecho.

Novoa, Y.L., 2016. “¿Son las convenciones de lucha contra la corrupción tratados de derechos humanos?", Themis: Revista de Derecho, 69: 301-314. Disponible en: https://dialnet.unirioja.es/descarga/articulo/5989823.pdf

Parsons, W., 2007. Políticas públicas. Una introducción a la teoria y la práctica del análisis de politicas públicas. México: Flacso-México.

Pelayo Möller, C.M., 2011. Introducción al Sistema Interamericano de Derechos Humanos. México: CNDH.

Pérez Triviño, J.L., 2018. "Whistleblowing y la lucha contra la corrupción en el deporte", en Millán Garrido, A., Derecho del fútbol: principios y normatividad. España: Reus, 121-137.

Pinto, M., 1997. Temas de derechos humanos. Buenos Aires: Editores del Puerto.

Pisarello, G., 2007. Los derechos sociales y sus garantias. Elementos para una reconstrucción. Madrid: Trotta.

Puñal, L. 2018. "Whistleblowing y Transparencia en el Sector Privado de Alemania", Dilemata, 27: 203-219. Disponible en: https://dialnet.unirioja.es/descarga/articulo/6543301.pdf

Rodríguez-Medel, C.R. 2019. "La protección de los informantes - whistleblowers - y las garantías de los investigados. Análisis de la propuesta de directiva de la Unión Europea y en España de la Proposición de Ley Integral de Lucha contra la Corrupción y Protección de los Denunciantes", Revista de Estudios Europeos, Extra 1: 225-245. Disponible en: http://www.ree-uva.es/images/numeros/20191/2019-em-1-225-245.pdf

Salazar, P., 2014. "Capítulo 7. La Reforma y las Políticas Públicas", en Salazar, P. (coord.) La Reforma Constitucional sobre Derechos Humanos: Una Guía Conceptual. México: Instituto Belisario Domínguez, 142-175.

Sandoval, I.E., 2010. "Papel de los informantes internos (Whistleblowers) en el combate a la corrupción", en Méndez-Silva, R., Lo que todos sabemos sobre la corrupción y algo más. México: UNAM, 199-210. 
Saxe, E.E., 1996. "Democracia, corrupción y crisis neoliberal en Latinoamérica", Travesias: Política, cultura y sociedad en Iberoamérica, 1: 153-163. Disponible en: https://dspace.unia.es/handle/10334/1565

Serrano, S., 2016. Guía de Estudio de la Materia Introducción al Estudio del Derecho Internacional de los Derechos Humanos. México: Flacso-México.

Serrano, S. y Vázquez, L. D., 2013. Los derechos en acción. Obligaciones y principios de derechos humanos. México: Flacso-México.

Uvalle Berrones, R., 2013. "Enfoque del Gobierno Cercano y Moderno en el Ámbito del Plan Nacional de Desarrollo 2013-2018", en Revista de Administración Pública 132: En torno a politicas generales para el desarrollo nacional y local, Volumen XLVIII, No. 3 (septiembre-diciembre 2013). México: INAP, 15-39. Disponible en: https://revistas-colaboracion.juridicas.unam.mx/index.php/rev-administracionpublica/issue/view/1204

Vázquez, L. D., 2018. Corrupción y Derechos Humanos: ¿por dónde comenzar la estrategia anticorrupción? Alemania: Peter Lang.

Villanueva, E. 2007. "Los Whistleblowers y el Estado de Derecho en México", en Fox, J. et al (Coords.). Derecho a Saber: Balance y Perspectivas Cívicas. México: Fundar-Centro de Análisis e Investigación - Woodrow Wilson International Center for Scholars, 371-374. Disponible en: https://fundar.org.mx/mexico/pdf/pdfsderechoasaber/sec8\%20ernesto\%20vill anueva.pdf 